This study investigated differences in the concepts of the expression of emotion held by Japanese and Australians for themselves and each other, both in terms of degree and kind of expressive behavior and in underlying dimensionality. Through a structured questionnaire, 80 Australian and 80 Japanese male and female students indicated how they thought they expressed eight emotions on 12 behaviors, and how someone of the other nationality would express them. Results show Australians were rated as more expressive by Japanese and that Japanese may conceptualize emotions as less intense. There was considerable agreement between the two groups on the level of expressivity of the Japanese. The dimensions of positive/negative, arousal and "affective focus" were shown to underlie the concepts and to distinguish the two national groups to varying degrees.

\title{
AUSTRALIAN AND JAPANESE CONCEPTS OF EXPRESSIVE BEHAVIOR
}

\author{
JEFFERY PITTAM \\ CYNTHIA GALLOIS \\ University of Queensland \\ SABURO IWAWAKI \\ Showa Women's University, Tokyo \\ PIETER KROONENBERG \\ University of Leiden
}

The expression of emotion is well documented, including considerable detail about cross-cultural similarities and differences. For some emotions, for example, facial expressions are used similarly in widely differing cultures and can be decoded accurately by members of different cultural groups (Ekman \& Friesen, 1975, 1978; Ekman, Friesen, \& Ellsworth, 1972; Izard, 1977). Such findings inevitably lead to the proposal that some of these behaviors are innate.

Although some expressive behaviors may be innate and similar across different cultures, there is considerable evidence suggesting the importance of social processes on emotional development (e.g., Barrett, 1993; Denham \& Grant, 1993). Cross-cultural differences have been reported for intensity, emotion judgments, display rules, and self-reports of emotion expression (Matsumoto, 1993), labeling (Matsumoto, 1992), and subjective experience (Scherer, Wallbott, \& Summerfield, 1986). Some expressive behaviors, then,

AUTHORS' NOTE: Correspondence concerning this article should be addressed to Jeffery Pittam, Department of English, University of Queensland, Brisbane, Australia, 4072.

JOURNAL OF CROSS-CULTURAL PSYCHOLOGY, Vol. 26 No. 5, September 1995 451-473

O 1995 Western Washington University 
are likely to be socially learned and may be mediated by norms and social rules (Argyle, Furnham, \& Graham, 1981). In addition, the ability to decode emotion may be determined by cultural distance. Shimoda, Argyle, and Ricci-Bitti (1978) found that their English and Italian participants could judge their own and each other's emotions quite well, but not those of Japanese. This accords with the conclusion drawn by Matsumoto, Wallbott, and Scherer (1989) that reports of emotional experience by people in a number of countries showed greater similarity between cultures that were geographically close, linguistically similar, and similar in terms of relative wealth.

Such examples suggest that socially learned rules of expressive behavior can mask innate effects (see Scherer, 1988). A clear example may be found in Friesen (1972), who found that Japanese mask negative expressions when an observer is present. Argyle (1988) also pointed out that Japanese have a display rule that one should not show negative emotions. That social rules may determine emotional expression suggests cultural differences in the conceptualization of the appropriateness of expressive behavior.

From within the current debate on the universality of facial expressions of emotion (see Ekman, 1994; Izard, 1994; Russell, 1994), Russell has noted the need to examine the way different cultures conceptualize emotions and emotional expression. Cross-cultural similarity in the actual expression of emotion and our ability to decode affect in ethnic out-groups suggest that there should be some similarity, at least in terms of the most salient behaviors. Thus, although the expression and perception of smiles may be culturally determined to some degree (Matsumoto \& Kudoh, 1993), broad smiling is likely to be part of the conceptual profile for happiness in all cultures. Different display rules held by cultures for other behaviors and emotions, however, may well be the primary determinant of the concepts held, resulting in cross-cultural differences of degree rather than necessarily of kind. Certainly, we would expect to find such differences at the level of emotional intensity (Izard, 1994; Matsumoto \& Ekman, 1989).

Support for the idea of masking may be found in Tomkins (1980), who suggested that a considerable amount of affect is neither acknowledged nor expressed, but rather is suppressed because of our ideas of what is appropriate. In addition, Averill (1984) and Epstein (1984) proposed that social norms influence the way we organize our emotional responses. Epstein goes on to say that our perceived response options are often more critical in determining emotional response than the stimulus situation itself. If this is so, then the way we think we express emotion is very important, particularly when the interaction is cross-cultural.

The aim of the present study was to examine cultural differences in the concepts of expressive behavior held by Australians and Japanese for them- 
selves and each other. Australians and Japanese are two culturally diverse groups that have increasing contact economically and as tourists. It is of some consequence, therefore, that we understand how each conceptualizes the expression of emotion. The study also asked whether members of each group believe that the other differs from themselves in the expression of emotion. If social factors do influence our conceptualizations, differences should be found. We looked for two types of differences: the kind and degree of expressive behaviors, and the dimensionality underlying these behaviors.

\section{EXPRESSTVE BEHAVIORS}

A range of behaviors using the vocal, facial, and body channels are involved in the actual expression of emotion. Twelve nonverbal behaviors were investigated in the present study. They were chosen, first, to represent these three channels, and second, because all have been cited in the literature as important markers of the emotions studied (see below). Six of the behaviors were vocal features: loudness, pitch, pitch variability, speech rate, vocal tension, and regularity of speech rhythm. Four were facial gestures: eye widening, eyebrow raising, gaze at interactant, and smiling. Two others were very broad characteristics representing the body channel: hand and arm movement, and general walking about.

Concepts of the expression of emotion may not match actual expression, of course, particularly if they are determined in part by social variables. It was felt, however, that although concepts for specific emotions may include behaviors other than those studied here, the ones selected would be those most likely to form part of these concepts.

The self-concept, particularly in relation to others, may have an impact on one's own emotional expression and that expected from others (Gallois, 1994). Markus and Kitayama (1991) argue that Westerners have a more independent self-concept than others such as Chinese and Japanese. Australians generally perceive themselves as happy-go-lucky and outgoing (Callan \& Gallois, 1983; Kippax \& Brigden, 1977). It is likely, then, that their concepts of emotion will include very expressive behavior. On the other hand, Japanese perceive themselves as cautious, reserved, and suppressive (Barnlund, 1975; Iwawaki \& Cowen, 1964), and Ekman (1973) proposed that Japanese control emotional reactions. In addition, Scherer, Wallbott, Matsumoto, and Kudoh (1988) found that Japanese students reported less expressiveness and fewer physiological symptoms than students in Europe and America. All these studies point to Japanese holding less expressive concepts. Further, Argyle (1988) proposed that Japanese are characterized by a lack of expressivity and that, as a result, Western people find Japanese inscrutable. This 
would suggest that not only Japanese but Australians also hold concepts involving less emotional expressivity for Japanese than for Australians.

In sum, then, we were looking for cross-cultural differences in kind and degree of these expressive behaviors, in the concepts our participants held for the emotions studied.

\section{DIMENSIONALITY OF CONCEPTS OF EXPRESSIVE BEHAVIOR}

Matsumoto (1989) proposed that the use of dimensions to represent cultural variability in the study of emotion may provide clues to differences in the cultures themselves. Matsumoto applied Hofstede's (1980) four dimensions of cultural variation to the perception of facial expression. In the present study, we used dimensions more traditionally associated with emotion to interpret participants' responses. The emotions selected for study were anger, contempt, fear, grief, love, respect, elation, and relief: four negative and four positive emotions. Despite claims for the independence of emotions such as elation and grief, the bipolarity (in particular, negative/positive) of mood states has recently been supported (Green, Goldman, \& Salovey, 1993). The bipolarity represents an underlying structure central to earlier models of emotional experience and affect trait words (e.g., Mehrabian \& Russell, 1974; Roseman, 1984; Scherer, 1982; Smith \& Ellsworth, 1985). Mehrabian and Russell (1974), for example, proposed three affect dimensions: pleasure (which in general ranged from positive to negative), arousal, and dominance. The first two of these have proven to be the most robust and have been included in more complex models (Daly, Lancee, \& Polivy, 1983; Russell, 1980). Russell's model has also received cross-cultural validation (Russell, Lewicka, \& Niit, 1989).

The emotions selected for this study may be described not only in terms of positive/negative but also arousal. Russell's (1991) review of the crosscultural evidence suggests these as possible universal dimensions in the conceptualization of emotion. The high arousal emotions examined here are anger, fear, elation, and love. The inclusion of love as a high-arousal emotion is supported by Pope (1980), who suggested that love can bring feelings of euphoric ecstasy or of peace and fulfillment. The low-arousal emotions are contempt, grief, respect, and relief. The present study tested the hypothesis that both Australian and Japanese participants' concepts of expressive behaviors for these emotions can also be described by this underlying twodimensional structure.

In terms of the actual expression of emotion, high-arousal negative emotions are characterized particularly by high pitch and pitch variability, fast 
rate, and high tension (Scherer, 1985, 1986) and low-arousal negative emotions by low pitch and slow rate (Scherer, 1985). The two positive low-arousal emotions studied (respect and relief) have not been linked to actual behaviors, but the high-arousal emotions are characterized particularly by high levels of smiling (Ekman \& Friesen, 1975; Shaver, Schwartz, Kirson, \& O'Connor, 1987). Specific emotions, of course, will use many more behaviors. The fact that we can point to differences in behavior based on these dimensions for the actual expression of emotion, however, suggests that concepts of expressive behavior may well be structured in similar ways.

\section{SUMMARY}

This study posed two research questions:

1. Are there differences of kind and degree in the concepts of expressive behavior held by Australians and Japanese for themselves and each other?

We expected that both Australians and Japanese would hold similar concepts of the expression of the eight emotions in terms of kind of behavior, but that differences of degree of expressivity would be found, with Japanese participants reporting less expressivity, and both groups ascribing less expressivity to Japanese than to Australians.

2. Can we describe the concepts of expressive behavior held by Australians and Japanese in terms of an underlying dimensionality and, if so, are there cross-cultural differences in this structure?

The different behaviors characterizing positive/negative and high/low arousal emotions, noted above, led us to expect that concepts of expressive behavior held by the two groups would be describable in terms of these dimensions. Nonetheless, we expected some cross-cultural differences in structure.

\section{METHOD}

\section{QUESTIONNAIRE}

Through a structured questionnaire, participants indicated how they thought they expressed the eight emotions using the 12 behaviors and how a 
member of the same age and gender as themselves but belonging to the other national group would express them.

The schedule used is described from the Australian point of view (Japanese participants completed the task in Japanese). Participants were asked to indicate on 5-point rating scales how they as Australians would use the 12 nonverbal behaviors in communicating each of the emotions in their everyday lives, and how they thought a Japanese would use them. Each emotion was presented on two adjacent pages of the questionnaire booklet. On the first, participants rated Australians; on the second, Japanese (this was reversed for the Japanese). To ensure that all participants, whether Japanese or Australian, were thinking of the same emotion, a single-sentence definition was given following the name of each emotion. Scales used for the six vocal behaviors, as well as eye widening and eyebrow raising, were bipolar; the remaining four scales were unipolar. For Japanese participants, the questionnaire was translated into Japanese and back-translated by two Japanese-English bilinguals working independently.

Scales were constructed using nontechnical terms (not numbers) for each scalar degree. Most of the expressive behaviors were self-explanatory (e.g., loudness) for both Australian and Japanese native participants. Where a problem might have existed with participants' understanding of the nonverbal concepts (e.g., pitch variability), the terms used for the scalar degrees helped clarify this. Thus the scale for pitch variability on the Australian questionnaire ranged from very monotonous to very variable. The Japanese questionnaire was constructed using similar principles.

\section{PARTICIPANTS}

Forty female and 40 male Australian-born students from The University of Queensland, Australia, and 40 female and 40 male students from the Hyogo University of Teacher Education, Japan, completed the self-administered questionnaire. Australian participants were all third-generation Australians at least. From their names and appearance, all seemed to be of Anglo-Celtic origin. They completed the task for credit in first-year psychology courses. Japanese students were all third-generation Japanese at least, and were all volunteers. Mean age of the Australians was 20.8 years $(S D=5.8$ years; range $17-41)$, and of the Japanese was 20.2 years $(S D=1.2$ years; range $18-23){ }^{1}$

\section{PROCEDURE}

Groups of up to 20 participants were present at each session. Instructions were printed on the front of each questionnaire booklet, but the task was 
explained in detail by the investigator at the start of each session. Ten different orders of emotions were used in the booklets to overcome order effects. The task took approximately $35-45$ minutes to complete.

\section{RESULTS AND DISCUSSION}

To examine differences of kind and degree, four-way MANOVAs were calculated for positive and negative emotions separately. The exploration of dimensionality was conducted using two-mode principal components analysis. The two sets of analyses are presented in that order.

\section{CROSS-CULTURAL DIFFERENCES OF KIND AND DEGREE}

Separate $2 \times 2 \times 4 \times 2$ factorial MANOVAs with 12 dependent variables (the expressive behaviors) were conducted for negative and positive emotions separately. Between-subjects variables were nationality (Australian or Japanese) and gender of participants, and emotions and nationality judged (Australian and Japanese) were repeated measures. A significance level of $p<$ .01 was used for all effects. Where significant multivariate effects were found, follow-up univariate ANOVAs were conducted, and where these were significant, analyses of simple effects were calculated. We were looking primarily for cross-cultural differences. In presenting the results, therefore, we will concentrate on these, mentioning other significant differences only when relevant to this principal aim. All significant multivariate effects are reported, however.

\section{Negative Emotions}

Significant multivariate main effects were found for nationality of participants (Wilks's lambda $=.224, F=41.88, d f=12,145, p<.001$ ); emotion (Wilks's lambda $=.164, F=31.63, d f=36,1350.99, p<.001$ ); and nationality judged (Wilks's lambda $=.441, F=15.34, d f=12,145, p<.001$ ). Averaged multivariate tests of significance are reported for effects containing the within-subjects variable of emotion (this procedure is adopted for all results presented). Significant two-way interactions were found between nationality and nationality judged (Wilks's lambda $=.648, F=6.57, d f=12,145$, $p<.001$ ) and nationality and emotion (Wilks's lambda $=.427, F=12.53$, $d f=36,1350.99, p<.001)$. In addition, a significant three-way interaction was found between nationality, nationality judged, and emotion (Wilks's lambda $=.797, F=3.00, d f=36,1350.99, p<.001)$. Table 1 presents the cell 
TABLE 1

Negative Emotions: Means on Expressive Behaviors for Two Nationalities and Two Nationalities Judged

\begin{tabular}{|c|c|c|c|c|c|c|c|c|c|}
\hline \multirow[b]{3}{*}{ Behavior } & \multirow{3}{*}{$\begin{array}{l}\text { Nationality } \\
\text { Judged }\end{array}$} & \multicolumn{8}{|c|}{ Emotion and Nationality } \\
\hline & & \multicolumn{2}{|c|}{ Anger } & \multicolumn{2}{|c|}{ Contempt } & \multicolumn{2}{|c|}{ Fear } & \multicolumn{2}{|c|}{ Grief } \\
\hline & & $A$ & $\boldsymbol{J}$ & $A$ & $J$ & $A$ & $J$ & $A$ & $J$ \\
\hline \multirow[t]{2}{*}{ Loudness } & A & $4.09+$ & $4.59^{*}$ & 3.30 & $3.35 *$ & $2.66 t$ & $3.56^{*}$ & $1.49+$ & $3.13^{*}$ \\
\hline & $\mathbf{J}$ & 4.03 & 4.05 & 2.95 & 2.76 & 2.81 & 2.86 & 1.88 & 1.90 \\
\hline \multirow[t]{2}{*}{ Pitch } & A & $3.15 * \dagger$ & $4.31^{*}$ & $2.54 \dagger$ & $3.25 *$ & $2.89+$ & 3.64 & $1.75 t$ & $2.70^{*}$ \\
\hline & J & 3.63 & 3.43 & 2.70 & 2.80 & 3.08 & 3.24 & 2.09 & 2.18 \\
\hline \multirow{2}{*}{$\begin{array}{l}\text { Pitch } \\
\text { variability }\end{array}$} & A & $3.69+$ & $4.26^{*}$ & $2.98+$ & $3.40^{*}$ & 3.44 & 3.49 & $2.33 \dagger$ & $3.14^{*}$ \\
\hline & J & 3.69 & 3.73 & 3.03 & 2.84 & 3.45 & 3.28 & 2.50 & 2.61 \\
\hline \multirow[t]{2}{*}{ Speech rate } & A & $3.75+$ & $4.49^{*}$ & $2.95^{*}$ & 3.33 & 3.71 & 3.58 & $2.00+$ & 2.54 \\
\hline & J & 4.16 & 4.00 & $3.38 t$ & 2.93 & 3.79 & 3.59 & 2.31 & 2.20 \\
\hline \multirow[t]{2}{*}{ Vocal tension } & A & 4.63 & $4.40^{*}$ & $3.89+$ & 3.26 & $4.64 t$ & 3.14 & $3.88 t$ & 2.24 \\
\hline & J & $4.49+$ & 4.00 & $3.89 \dagger$ & 2.90 & $4.35 t$ & 2.81 & $3.83+$ & 1.85 \\
\hline \multirow[t]{2}{*}{ Speech rhythm } & n $A$ & 2.73 & 2.43 & 3.15 & 2.79 & 2.09 & 2.15 & 2.36 & 2.18 \\
\hline & J & 2.74 & 2.45 & 3.05 & 2.96 & 2.19 & 1.93 & 2.33 & 2.04 \\
\hline \multirow[t]{2}{*}{ Gaze } & A & 3.89 & $4.23^{*}$ & 3.26 & $3.36^{*}$ & 3.10 & $2.89^{*}$ & $2.18 \dagger$ & $2.71 *$ \\
\hline & J & 3.75 & 3.76 & 3.14 & 2.80 & $2.89+$ & 2.10 & $1.99 \dagger$ & 2.19 \\
\hline \multirow[t]{2}{*}{ Smiling } & A & 1.08 & 1.35 & $1.24 \uparrow$ & 2.66 & 1.23 & 1.30 & 1.21 & 1.34 \\
\hline & J & 1.23 & 1.18 & $1.24 \dagger$ & 2.39 & 1.16 & 1.21 & 1.13 & 1.31 \\
\hline \multirow[t]{2}{*}{ Eye widening } & A & $2.09+$ & $3.84^{*}$ & $1.94 \dagger$ & 3.00 & $3.43^{*}$ & 3.44 & 2.36 & 2.43 \\
\hline & $\mathbf{J}$ & $2.10+$ & 3.10 & $1.75 t$ & 2.71 & 2.83 & 3.01 & 2.05 & 2.25 \\
\hline \multirow{2}{*}{$\begin{array}{l}\text { Eyebrow } \\
\text { raising }\end{array}$} & A & $2.19+$ & $4.01 *$ & $2.25 t$ & 3.16 & 3.40 & 3.19 & 2.14 & 2.16 \\
\hline & J & $2.24 t$ & 3.53 & $2.01 t$ & 3.10 & 3.14 & 2.80 & 1.99 & 2.24 \\
\hline \multirow{2}{*}{$\begin{array}{l}\text { Hand/arm } \\
\text { movement }\end{array}$} & A & $3.59+$ & $4.28^{*}$ & $2.39 t$ & $3.21 *$ & $2.66 t$ & $3.48^{*}$ & $2.05 t$ & $3.50^{*}$ \\
\hline & J & 3.49 & 3.14 & 2.31 & 2.40 & 2.75 & 2.50 & 1.98 & 1.91 \\
\hline \multirow[t]{2}{*}{ Walking about } & A & $3.04 \dagger$ & $3.78^{*}$ & $1.89+$ & $2.64^{*}$ & $2.64 t$ & $3.09^{*}$ & $1.65 t$ & $3.68^{*}$ \\
\hline & J & 2.85 & 2.49 & 2.00 & 1.96 & 2.48 & 2.26 & 1.73 & 1.61 \\
\hline
\end{tabular}

NOTES: $\mathrm{A}=$ Australian; $\mathrm{J}=$ Japanese.

${ }^{*} p<.01$, significance levels refer to each vertical pair of means.

$t p<.01$, significance levels refer to horizontal pairs of means (the value marked plus the one to its right).

means for the two nationalities and nationalities judged for all 12 behaviors on each emotion.

The three-way interaction shows that five expressive behaviors contributed significantly to this effect. These were loudness, pitch, speech rate, eye widening, and eyebrow raising. Essentially, however, the solution was a Nationality $\times$ Nationality Judged two-way effect, even for these five behaviors. The two-way interaction shows that the Japanese participants consistently rated Australians as significantly more expressive than Japanese not 
only on these five behaviors but also on pitch variability, vocal tension, and gaze. This is reflected in Table 1 although, as can be seen, the differences are not always significant at the $p<.01$ level. Australian participants rated Japanese either as more expressive than themselves, or at least as nonsignificantly different. Overall, therefore, there was a tendency for each participant group to rate the other as more expressive.

There was, in addition, considerable agreement between the two participant groups on how expressive the Japanese were. Again, Table 1 reflects this, with vocal tension being the only clear exception. For all four emotions, the Australian participants rated Japanese as using significantly more vocal tension than themselves. This applies particularly to the high-arousal emotions of anger and fear.

In general, and unlike the Japanese, the Australian participants saw very few significant differences between the two national groups for the negative emotions. There were 41 significant cross-cultural differences $(43 \%$ of possible differences), 20 on the vocal channel and 21 on the nonvocal. On both channels there were more cross-cultural differences in the ratings for Australians (14 each vocal and nonvocal) than for Japanese. Overall, our prediction that Australians' concepts of themselves would be very expressive was not borne out for the negative emotions. Both groups of participants, however, as predicted, proposed similar and low expressivity for Japanese.

\section{Positive Emotions}

Significant multivariate main effects were found for nationality of participant (Wilks's lambda $=.287, F=30.05, d f=12,145, p<.001$ ); emotion (Wilks's lambda $=.182, F=29.28, d f=36,1350.99, p<.001$ ); and nationality judged (Wilks's lambda $=.360, F=21.52, d f=12,145, p<.001$ ). Significant two-way interactions were found between nationality and nationality judged (Wilks's lambda $=.609, F=7.74, d f=12,145, p<.001$ ); nationality and emotion (Wilks's lambda $=.567, F=7.93, d f=36,1350.99, p<.001$ ); and nationality judged and emotion (Wilks's lambda $=.787, F=3.18, d f=36$, $1350.99, p<.001)$. In addition, a significant three-way interaction was found between nationality, nationality judged, and emotion (Wilks's lambda $=.774$, $F=3.41, d f=36,1350.99, p<.001$ ). Table 2 presents the cell means for the two nationalities and nationalities judged for all 12 behaviors on each emotion.

Unlike the solution for the negative emotions, the solution for the positive emotions is essentially a three-way effect. This interaction shows that eight expressive behaviors contributed significantly: loudness, pitch, pitch variability, speech rate, vocal tension, gaze, hand and arm movement, and 
TABLE 2

Positive Emotions: Means on Expressive Behaviors for Two Nationalities and Two Nationalities Judged

\begin{tabular}{|c|c|c|c|c|c|c|c|c|c|}
\hline \multirow[b]{3}{*}{ Behavior } & \multirow{3}{*}{$\begin{array}{l}\text { Nationality } \\
\text { Judged }\end{array}$} & \multicolumn{8}{|c|}{ Emotion and Nationality } \\
\hline & & \multicolumn{2}{|c|}{ Love } & \multicolumn{2}{|c|}{ Respect } & \multicolumn{2}{|c|}{ Elation } & \multicolumn{2}{|c|}{ Relief } \\
\hline & & $A$ & $J$ & $A$ & $J$ & $A$ & $\boldsymbol{J}$ & $A$ & $\boldsymbol{J}$ \\
\hline \multirow[t]{2}{*}{ Loudness } & A & $2.13+$ & $3.74^{*}$ & $2.49 * \dagger$ & $3.86^{*}$ & $4.58^{*}$ & $4.54^{*}$ & 2.95 & $3.18^{*}$ \\
\hline & J & 2.28 & 2.54 & $2.00 \dagger$ & 3.23 & 4.15 & 4.09 & $2.88 \dagger$ & 2.49 \\
\hline \multirow[t]{2}{*}{ Pitch } & $\mathbf{A}$ & $2.45 t$ & $3.54^{*}$ & $2.64 t$ & $3.70^{*}$ & 4.04 & $4.34^{*}$ & 2.78 & 2.99 \\
\hline & J & 2.74 & 2.78 & $2.46+$ & 3.21 & 4.09 & 3.86 & 2.93 & 2.68 \\
\hline \multirow{2}{*}{$\begin{array}{l}\text { Pitch } \\
\text { variability }\end{array}$} & A & $3.46 t$ & $3.86^{*}$ & $3.20+$ & $3.66^{*}$ & $4.49^{*}$ & 4.31 & 3.29 & $3.18 *$ \\
\hline & J & 3.15 & 3.20 & 2.99 & 3.19 & 4.00 & 4.05 & $3.24 \uparrow$ & 2.74 \\
\hline \multirow[t]{2}{*}{ Speech rate } & A & 2.71 & $3.06^{*}$ & 2.90 & $3.19 *$ & 4.28 & 4.10 & 3.04 & $2.78^{*}$ \\
\hline & J & 3.03 & 2.65 & 2.85 & 2.78 & $4.38 t$ & 3.91 & $3.33 t$ & 2.35 \\
\hline \multirow[t]{2}{*}{ Vocal tension } & A & $2.34 *+$ & $4.06^{*}$ & $3.26 t$ & $4.00^{*}$ & $2.75 t$ & 4.50 & $2.51 \dagger$ & 3.03 \\
\hline & $\mathbf{J}$ & $2.94 t$ & 3.50 & 3.45 & 3.53 & $3.18 t$ & 4.35 & 2.63 & 2.81 \\
\hline \multirow{2}{*}{$\begin{array}{l}\text { Speech } \\
\text { thythm }\end{array}$} & A & 3.15 & 2.98 & 3.11 & 3.50 & $2.50 t$ & 3.00 & 2.84 & 3.15 \\
\hline & J & 2.98 & 2.74 & 3.13 & 3.50 & 2.90 & 2.94 & 2.81 & 3.01 \\
\hline \multirow[t]{2}{*}{ Gaze } & A & $4.28^{*}$ & $4.53^{*}$ & $3.46 *+$ & $4.36^{*}$ & 3.95 & 4.36 & $3.08+$ & 3.61 \\
\hline & $\mathbf{J}$ & 3.70 & 3.33 & $2.95+$ & 3.91 & 3.63 & 4.02 & 3.01 & 3.21 \\
\hline \multirow[t]{2}{*}{ Smiling } & A & 3.76 & 3.41 & $2.89+$ & $3.34^{*}$ & 4.64 & 4.38 & 3.33 & 3.26 \\
\hline & J & 3.48 & 3.20 & 2.53 & 2.81 & 4.35 & 4.23 & 3.15 & 3.05 \\
\hline \multirow[t]{2}{*}{ Eye widening } & A & $3.78 *$ & $3.71 *$ & $3.49^{*}$ & 3.70 & $4.46^{*}$ & 4.25 & 3.34 & 2.99 \\
\hline & J & 3.31 & 3.19 & 3.04 & 3.40 & 3.99 & 3.78 & 3.15 & 2.78 \\
\hline \multirow{2}{*}{$\begin{array}{l}\text { Eyebrow } \\
\text { raising }\end{array}$} & A & 3.50 & 3.16 & 3.36 & 3.36 & $4.28 t$ & 3.58 & $3.19 t$ & 2.74 \\
\hline & J & $3.43 t$ & 2.91 & 3.09 & 3.15 & $4.13+$ & 3.31 & $3.31+$ & 2.70 \\
\hline \multirow{2}{*}{$\begin{array}{l}\text { Hand/arm } \\
\text { movement }\end{array}$} & A & $3.28 *+$ & $3.99^{*}$ & $2.60+$ & $3.64^{*}$ & $4.20^{*}$ & $4.38^{*}$ & 2.88 & $3.20^{*}$ \\
\hline & J & 2.86 & 2.76 & 2.23 & 2.63 & 3.68 & 3.84 & 2.75 & 2.43 \\
\hline \multirow[t]{2}{*}{ Walking about } & A & $1.99+$ & $3.05^{*}$ & $1.69+$ & $2.54^{*}$ & $3.71^{*}$ & $3.73^{*}$ & 2.34 & $2.50^{*}$ \\
\hline & $\mathbf{J}$ & 1.95 & 2.11 & 1.61 & 1.69 & 3.19 & 3.08 & 2.23 & 1.89 \\
\hline
\end{tabular}

NOTE: $\mathrm{A}=$ Australian; $\mathrm{J}=$ Japanese.

$* p<.01$, significance levels refer to each vertical pair of means.

$t p<.01$, significance levels refer to horizontal pairs of means (the value marked plus the one to its right).

walking about. Once again, Japanese participants rated Australians as significantly more expressive than themselves for many of the behaviors. This is shown in Table 2.

There was considerable agreement by both participant groups that Australians were more expressive than Japanese, although the Australian participants' ratings were attenuated for loudness, pitch variability, gaze, hand and arm movement, and walking about. Exceptions to the general pattern included speech rate and pitch variability, and involved the emotions of elation 
and relief. Japanese rated Australians as lower than themselves on speech rate for both emotions and lower on pitch variability for relief.

Once again, Australian participants saw fewer differences between the two national groups than did the Japanese, although overall they saw more differences than they had for the negative emotions. In terms of overall cross-cultural differences, there were 32 for positive emotions (33\% of possible differences), somewhat fewer than for the negative emotions. Of these, 19 were on the vocal channel (10 for ratings of Australians) and 13 on the nonvocal channel ( 9 for ratings of Australians). In general, then, results for positive emotions were closer to our predictions than they were for the negative emotions, with Australians rating themselves as more expressive than Japanese, and Japanese, as before, rating Australians as more expressive than themselves.

\section{CROSS-CULTURAL DIFFERENCES IN UNDERLYING DIMENSIONALITY}

We examined the dimensionality underlying the expressive behaviors using a form of multimode principal components analysis in which components or dimensions are computed for two modes only. The two modes in the present study were the emotions (Mode 1) and the expressive behaviors (Mode 2). The analyses reported were conducted using the program TUCKALS2 (Kroonenberg \& Brouwer, 1985). The basic aim of this program is reduction of the data to a limited number of components or dimensions for each mode, the assumption being that these components can describe the systematic variability in each mode. This gave an 8 (the emotions) $\times 24$ (the 12 behaviors for the two nationalities judged) matrix. Separate analyses were conducted for Australian and Japanese participants. Although this does not compare the two national groups directly, it gives a clearer idea of the structures underlying the data for each.

A series of analyses were conducted for each participant group to determine the number of components that provided both an adequate fit and interpretation of the data. A solution with four components each for emotions and behaviors was selected for both sets of data. No formal procedures to decide the most appropriate solution are available at present. However, the 4 $\times 4$ solutions gave the best fit in each case, being superior to solutions involving two, three, and five components for each mode.

The model is solved by least squares methods and, therefore, allows the standard division of the sums of squares into fitted and residual. A multiple correlation between data and fitted data is calculated. The solution reported here for the Australian participants had an $R^{2}$ of .48 , and for the Japanese 
TABLE 3

Independent Contributions of Each Component to the Overall Multiple Correlation for Both Data Sets

\begin{tabular}{|c|c|c|c|c|c|c|c|c|}
\hline \multirow[b]{2}{*}{ Participants } & \multicolumn{4}{|c|}{ Emotions } & \multicolumn{4}{|c|}{ Behaviors } \\
\hline & 1 & 2 & 3 & 4 & $I$ & 2 & 3 & 4 \\
\hline Australians & 0.26 & 0.10 & 0.09 & 0.03 & 0.24 & 0.13 & 0.08 & 0.03 \\
\hline Japanese & 0.20 & 0.08 & 0.05 & 0.04 & 0.19 & 0.07 & 0.06 & 0.05 \\
\hline
\end{tabular}

participants, an $R^{2}$ of .37 . These are fairly typical of such applications (Kroonenberg, 1983; Law, Snyder, Hattie, \& McDonald, 1984).

The components of each mode partition the overall multiple correlation into independent contributions. These are given in Table 3. As would be expected in a principal components analysis, Component 1 in each case explains the most variance.

\section{Dimensionality of Mode 1: The Eight Emotions}

Figure 1 plots Component 1 of the emotion mode against each of the other three components of this mode for each data set. In this part of the analysis, ratings for all behaviors and for both nationalities judged are collapsed across each emotion. The idea is to explore the dimensionality underlying the emotions, based on the ratings of the expressive behaviors. Emotions are shown as vectors in the multidimensional space. It should be remembered that each participant group was using the same definition of each emotion.

For both participant groups, Component 1 is a positive/negative dimension, revealing the importance of this dimension to the participants' concepts of expressive behavior. From the values in Table 3, Component 1 for the emotion mode can be seen to explain approximately $54 \%$ of the total explained variance for each data set. The result indicates that concepts of expressive behavior are related to emotions in ways that are in part determined by the capacity of the behaviors to express positivity or negativity.

Component 2 appears to be an arousal dimension. For the Japanese data this is quite clear, with anger, fear, love, and elation opposed to contempt, grief, respect, and relief, although love and fear loaded relatively low on this component. The picture is not as clear for the Australian data. Component 2 separates particularly anger and elation from grief and respect. Contempt is also on the expected side of the midpoint, but only just. The other three emotions, however, are on the wrong side of the midpoint. Even so, it seems fair to say that two of Mehrabian and Russell's (1974) dimensions-pleasure 


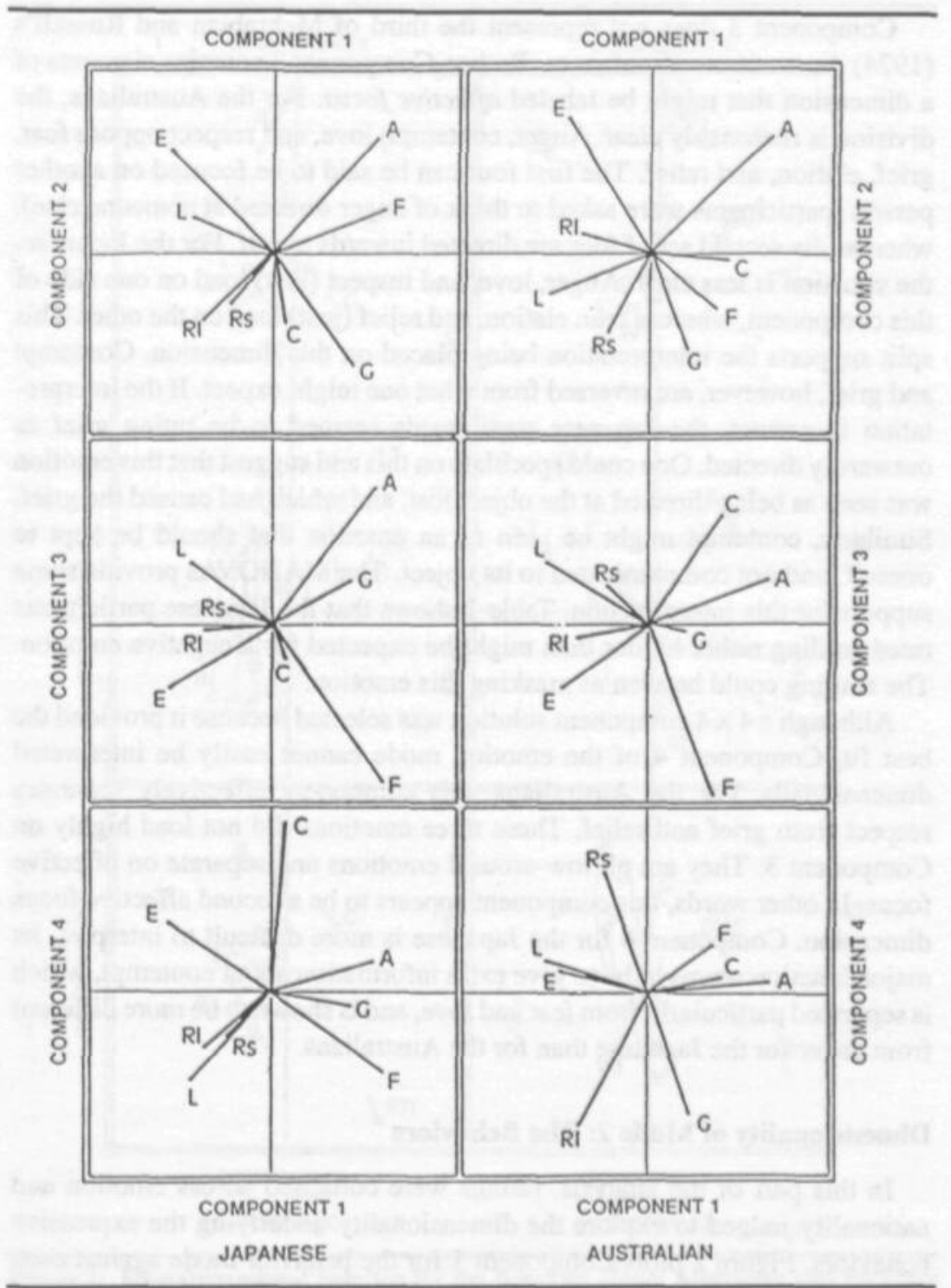

Figure 1: Four-Dimensional Solution for the Emotion Mode: Australian and Japanese Data Sets

NOTE: $\mathrm{A}=$ anger; $\mathrm{C}=$ contempt; $\mathrm{F}=$ fear; $\mathrm{G}=$ grief; $\mathrm{L}=$ love; $\mathrm{Rs}=$ respect; $\mathrm{E}=$ elation; $\mathrm{Rl}=$ relief.

(positive/negative) and arousal-have been shown to have importance to the concepts we hold of the expression of emotion in terms of expressive behavior. 
Component 3 does not represent the third of Mehrabian and Russell's (1974) dimensions - dominance. Rather, Component 3 contains elements of a dimension that might be labeled affective focus. For the Australians, the division is reasonably clear. Anger, contempt, love, and respect oppose fear, grief, elation, and relief. The first four can be said to be focused on another person (participants were asked to think of anger directed at someone else), whereas the second set of four are directed inwards to self. For the Japanese, the situation is less clear. Anger, love, and respect (just) load on one side of this component, whereas fear, elation, and relief (just) load on the other. This split supports the interpretation being placed on this dimension. Contempt and grief, however, are reversed from what one might expect. If the interpretation is correct, the Japanese participants seemed to be rating grief as outwardly directed. One could speculate on this and suggest that this emotion was seen as being directed at the object lost, and which had caused the grief. Similarly, contempt might be seen as an emotion that should be kept to oneself, and not communicated to its object. The MANOVAs provide some support for this interpretation. Table 1 shows that the Japanese participants rated smiling rather higher than might be expected for a negative emotion. The smiling could be seen as masking this emotion.

Although a $4 \times 4$ component solution was selected because it provided the best fit, Component 4 of the emotion mode cannot easily be interpreted dimensionally. For the Australians, this component effectively separates respect from grief and relief. These three emotions did not load highly on Component 3. They are all low-arousal emotions and separate on affective focus. In other words, this component appears to be a second affective focus dimension. Component 4 for the Japanese is more difficult to interpret. Its major function seems to be to give extra information about contempt, which is separated particularly from fear and love, and is shown to be more different from anger for the Japanese than for the Australians.

\section{Dimensionality of Mode 2: The Behaviors}

In this part of the analysis, ratings were collapsed across emotion and nationality judged to explore the dimensionality underlying the expressive behaviors. Figure 2 plots Component 1 for the behavior mode against each of the other modes for both data sets. As this figure shows, the higher level components ( 1 and 2 ) are characterized simply by sets of behaviors that have no apparent underlying dimensional structure. However, as is detailed below, Component 3 for the Japanese and Component 4 for the Australians separate the two nationalities judged on several of the same behaviors. 


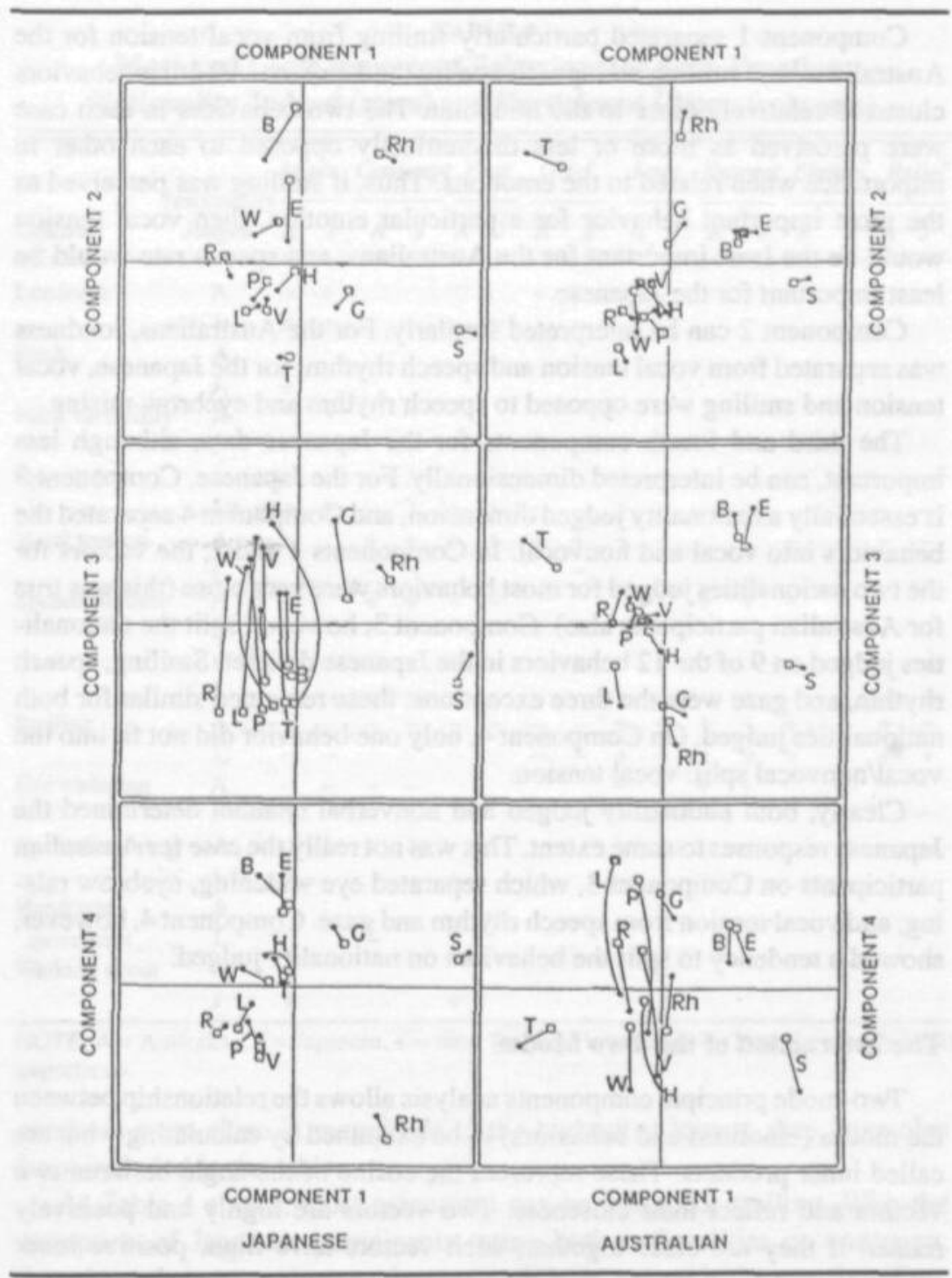

Figure 2: Four-Dimensional Solution for the Behavior Mode: Australian and Japanese Data Sets

NOTE: $\mathrm{L}=$ loudness; $\mathrm{P}=$ pitch; $\mathrm{V}=$ pitch variation; $\mathrm{R}=$ speech rate; $\mathrm{T}=$ vocal tension; $\mathrm{Rh}=$ speech rhythm; $\mathbf{G}=$ gaze; $S=$ smiling; $\mathrm{E}=$ eye widening; $\mathrm{B}=$ eyebrow raising; $\mathbf{H}=$ hand/arm movement; $W=$ walking about.

$\square=$ ratings of Japanese; $\bullet=$ ratings of Australians, Pairs of ratings are shown joined. 
Component 1 separated particularly smiling from vocal tension for the Australians, and smiling and speech rate for the Japanese. All other behaviors clustered relatively close to the midpoint. The two behaviors in each case were perceived as more or less diametrically opposed to each other in importance when related to the emotions. Thus, if smiling was perceived as the most important behavior for a particular emotion, then vocal tension would be the least important for the Australians, and speech rate would be least important for the Japanese.

Component 2 can be interpreted similarly. For the Australians, loudness was separated from vocal tension and speech rhythm; for the Japanese, vocal tension and smiling were opposed to speech rhythm and eyebrow raising.

The third and fourth components for the Japanese data, although less important, can be interpreted dimensionally. For the Japanese, Component 3 is essentially a nationality judged dimension, and Component 4 separated the behaviors into vocal and nonvocal. In Components 1 and 2 , the vectors for the two nationalities judged for most behaviors were very close (this was true for Australian participants also). Component 3, however, split the nationalities judged on 9 of the 12 behaviors in the Japanese data set. Smiling, speech rhythm, and gaze were the three exceptions; these remained similar for both nationalities judged. On Component 4 , only one behavior did not fit into the vocal/nonvocal split: vocal tension.

Clearly, both nationality judged and nonverbal channel determined the Japanese responses to some extent. This was not really the case for Australian participants on Component 3 , which separated eye widening, eyebrow raising, and vocal tension from speech rhythm and gaze. Component 4 , however, showed a tendency to split the behaviors on nationality judged.

\section{The Interaction of the Two Modes}

Two-mode principal components analysis allows the relationship between the modes (emotions and behaviors) to be examined by calculating what are called inner products. These represent the cosine of the angle between two vectors and reflect their closeness. Two vectors are highly and positively related if they are close together; such vectors have high, positive inner products, and the concepts that the vectors represent are important to one another. Conversely, when two vectors have a high, negative inner product, they are inversely related, and the two concepts have little or no importance to one another.

Table 4 shows which behaviors were perceived as most important (had the highest positive inner products) and the least important (had the highest negative inner products) to each emotion. Where the values of other inner 
TABLE 4

Most and Least Important Behaviors for Each Emotion: Nationality Judged (rows) and Participant Group (columns)

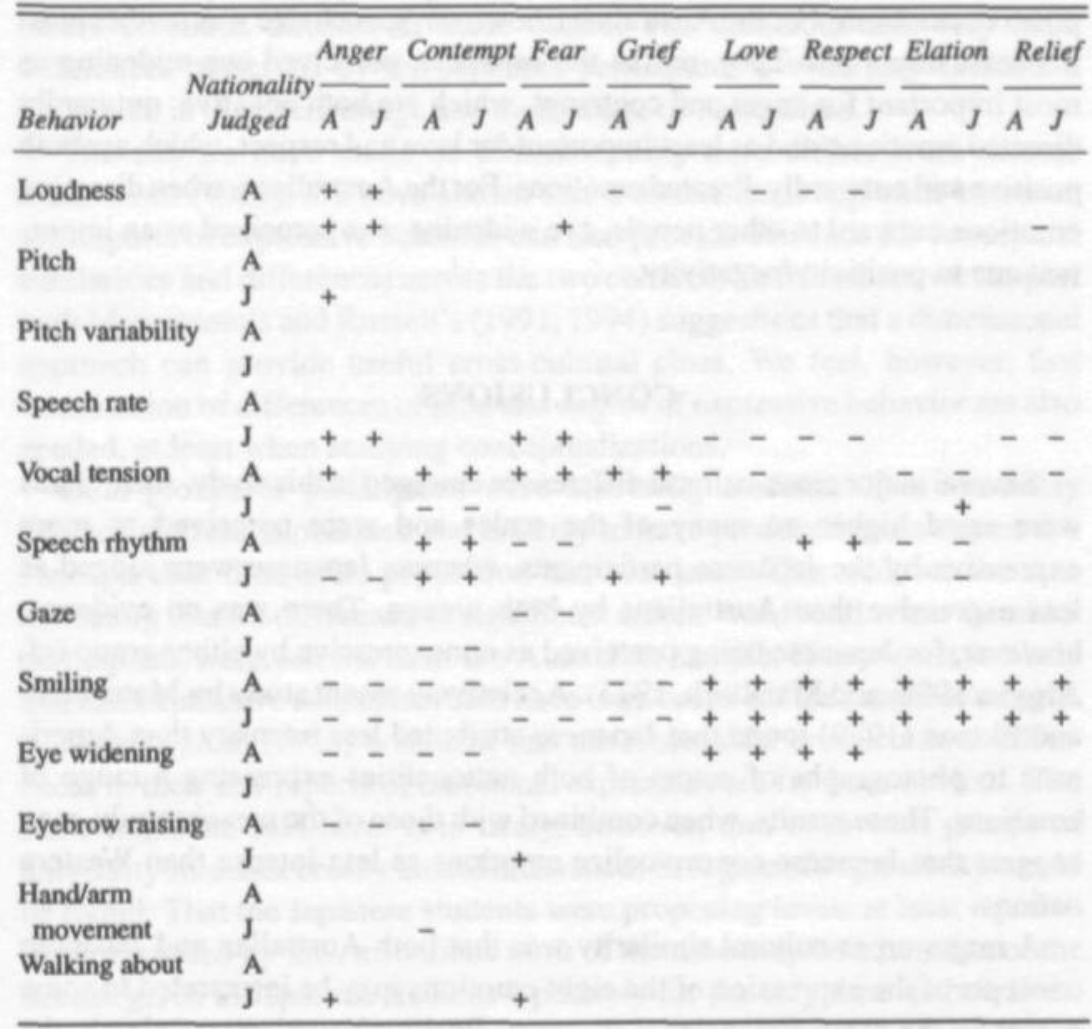

NOTE: $\mathbf{A}=$ Australian; $\mathbf{J}=$ Japanese. $+=$ most (or very) important; $-=$ least (or of very little) importance.

products were close in magnitude to the highest or lowest, they have also been included in the table.

As Table 4 shows, most agreement can be found for smiling. With the exception of Japanese participants rating both nationalities on contempt, there is total agreement across the two participant groups in the use of smiling. The one exception is interesting, and supports the earlier result found in the MANOVAs. Japanese participants appear to have believed that smiling has some importance for contempt, giving rise perhaps to the stereotype of inscrutability held by some Westerners for Japanese (see Argyle, 1988).

The most common form of difference in Table 4 is where one national group has rated a behavior as most or least important, whereas for the other 
group of participants, the behavior had less salience. Thus Japanese participants perceived speech rate as most important for anger and fear-both negative, high-arousal emotions - and as least important for three of the four positive emotions. For the Australians, however, speech rate was neither most nor least important. They, unlike the Japanese, perceived eye widening as most important for anger and contempt, which are both negative, outwardly directed emotions, and as least important for love and respect, which are both positive and outwardly directed emotions. For the Australians, when directing emotions outward to other people, eye widening was perceived as an important cue to positivity/negativity.

\section{CONCLUSIONS}

Several major cross-cultural differences emerged in this study. Australians were rated higher on many of the scales and were perceived as more expressive by the Japanese participants, whereas Japanese were judged as less expressive than Australians by both groups. There was no evidence, however, for Japanese being perceived as nonexpressive by either group (cf. Argyle, 1988, and Marsbach, 1973). A relatively recent study by Matsumoto and Ekman (1989) found that Japanese attributed less intensity than Americans to photographs of actors of both nationalities expressing a range of emotions. These results, when combined with those of the present study, may suggest that Japanese conceptualize emotions as less intense than Western nations.

A major cross-cultural similarity was that both Australian and Japanese concepts of the expression of the eight emotions may be interpreted to some extent by the same dimensional structure. Positive/negative was clearly the major distinguishing parameter in each case, reflecting the ability of the behaviors to represent positivity and negativity. Arousal was also important, and a possible new dimension-affective focus - was revealed. The biggest differences between the two participant groups occurred in the behavior mode at the level of Components 3 and 4, with Japanese participants' ratings being influenced by both the nationality they were judging and the nonverbal channel. The first of these was also reflected in the fact that Japanese participants perceived more differences across nationality judged than did Australians.

Relating the behaviors to the dimensions shows that the major difference for Australian participants was that there were more nationality judged differences for positive emotions than for negative ones. No such clear dimensional division emerged for the Japanese, although there was a definite 
tendency for them to perceive more nationality judged differences on outwardly directed emotions than on inwardly directed emotions. This may be related to a Japanese self-image that includes a reluctance to communicate to others emotions directed at those others. The numerous and very clear differences perceived by the Japanese participants overall may indicate a difference in their self-image and their image of Australians.

The use we have made of dimensionality here differs from that of Matsumoto (1989). We have shown that a dimensional approach based on self-reports of expressive behavior can also provide evidence for conceptual similarities and differences across the two cultures. To this extent we support both Matsumoto's and Russell's $(1991,1994)$ suggestions that a dimensional approach can provide useful cross-cultural clues. We feel, however, that examination of differences of kind and degree of expressive behavior are also needed, at least when studying conceptualizations.

Both groups of participants were university students. This inevitably affected the results obtained and is likely to have produced more expressive concepts than if an older population had been used. That said, see the note indicating that no difference in significant effects was found when the older participants were deleted from the Australian sample. However, it is likely that less expressive concepts would have been found for the Japanese sample.

Scherer et al. (1988) comment that the reasons for cross-cultural differences in their self-reports of emotional expression are far from obvious. The same might be said here. It is likely, however, that even with groups of university students, cross-cultural differences in degree of expressivity would be found. That the Japanese students were proposing levels at least equal to those proposed by the Australians most of the time may be a function of the license given to Japanese students-possibly for the only time in their lives. Barnlund's (1989) work on interaction among American and Japanese college students has indicated that Japanese students are not typical of the whole population. The findings here seem to support this, but a detailed comparison of student and other groups in concepts held of the expression of emotion must be a task for future research.

Finally, one factor that may have a bearing on the results obtained here is the extent of knowledge each group had of the other's culture. In Australia, Japanese are seen regularly as tourists, business people, and students. Australian students have many opportunities to interact with their Japanese counterparts. The Japanese students, however, may have known far less about Australians. Pittam, Kashima, and Iwawaki (1990), in a study of auto- and heterostereotypes, found that Japanese held an ethnic stereotype of Australians that did not differ from one held of Canadians. The stereotype was, in other words, a broadly based Western stereotype, rather than a national 
Australian stereotype. It may be that participants used in the present study did not have a clear picture of Australians, proposing, as a result, broadly based stereotypic concepts of expressive behavior perceived as appropriate to Westerners in general. Once again, however, this is an area that must be left for future research.

\section{NOTE}

1. The Australian participants' distribution of ages was skewed to the right with 16 of the 80 being 24 years or older. To check if this difference in the participant groups affected the results, the four-way MANOVAs were calculated with the responses from these 16 Australians dropped from the data set. The same results were obtained, with the same effects being significant. As a result, the full data set was used in the analyses presented.

\section{REFERENCES}

Argyle, M. (1988). Bodily communication (2nd ed.), London: Methuen.

Argyle, M., Furnham, A., \& Graham, J. A. (1981). Social situations. Cambridge: Cambridge University Press.

Averill, J. R. (1984). The acquisition of emotions during childhood. In C. Z. Malatesta \& C. E. Izard (Eds.), Emotion in adult development (pp. 23-43), Beverly Hills, CA: Sage.

Barnlund, D. C. (1975). Communicative styles in two cultures: Japan and the United States. In A. Kendon, R. M. Harris, \& M. R. Key (Eds.), Organization of behavior in face-to-face interaction (pp. 427-456). The Hague, Netherlands: Mouton.

Barnlund, D. C. (1989). Communicative styles of Japanese and Americans: Images and realities. Belmont, CA: Wadsworth.

Barrett, K. C. (1993). The development of nonverbal communication of emotion: A functionalist perspective. Journal of Nonverbal Behavior, 17, 145-169.

Callan, V. J., \& Gallois, C. (1983). Ethnic stereotypes: Australian and Southern-European youth. Journal of Social Psychology, 119, 287-288.

Denham, S. A., \& Grant, L. (1993). Socialization of emotion: Pathway to preschoolers' emotional and social competence. Journal of Nonverbal Behavior, 17, 205-277.

Daly, E. M., Lancee, W. J., \& Polivy, J. (1983). A conical model for the taxonomy of emotional experience. Joumal of Personality and Social Psychology, 45, 443-457.

Ekman, P. (1973). Darwin and cross-cultural studies of facial expression. In P. Ekman (Ed.), Darwin and facial expression (pp. 1-83). New York: Academic Press.

Ekman, P. (1994). Strong evidence for universals in facial expressions: A reply to Russell's mistaken critique. Psychological Bulletin, 115, 268-287.

Ekman, P., \& Friesen, W. V. (1975). Unmasking the face: A guide to recognizing emotions from facial clues. Englewood Cliffs, NJ: Prentice-Hall.

Ekman, P., \& Friesen, W. V. (1978). Manual for the facial action system. Palo Alto, CA: Consulting Psychologists Press.

Ekman, P., Friesen, W. V., \& Ellsworth, P. (1972). Emotion in the human face: Guidelines for research and $a$ review of findings. New York: Pergamon. 
Epstein, S. (1984). Controversial issues in emotion theory. In P. Shaver (Ed.), Review of personality and social psychology: Vol. 5. Emotions, relationships and health (pp. 64-88). Beverly Hills, CA: Sage.

Friesen, W. V. (1972). Cultural differences in facial expressions in a social situation: An experimental test of the concept of display rules. Unpublished doctoral dissertation, University of California, San Francisco.

Gallois, C. (1994). Group membership, social rules, and power: A social-psychological perspective on emotional communication. Joumal of Pragmatics, 22, 301-324.

Green, D. P., Goldman, S. L., \& Salovey, P. (1993). Measurement error masks bipolarity in affect ratings. Journal of Personality and Social Psychology, 64, 1029-1041.

Hofstede, G. (1980). Culture's consequences: International differences in work-related values. Beverly Hills, CA: Sage.

Iwawaki, S., \& Cowen, E. L. (1964). The social desirability of trait-descriptive terms: Applications to a Japanese sample. Joumal of Social Psychology, 63, 199-205.

Izard, C. E. (1977). Human emotions. New York: Plenum.

Izard, C. E. (1994). Innate and universal facial expressions: Evidence from developmental and cross-cultural research. Psychological Bulletin, 115, 288-299.

Kippax, S., \& Brigden, D. (1977). Australian stereotyping - A comparison. Australian Journal of Psychology, 29, 89-96.

Kroonenberg, P. M. (1983). Three-mode principal components analysis: Theory and applications. Leiden: DSWO Press.

Kroonenberg, P. M., \& Brouwer, P. (1985). User's guide to TUCKALS3. Leiden, the Netherlands: University of Leiden.

Law, H. G., Snyder, C. W., Jr., Hattic, J. A., \& McDonald, P. M. (1984). Research methods for multimode data analysis. New York: Praeger.

Markus, H. R., \& Kitayama, S. (1991). Culture and the self: Implications for cognition, emotion and motivation. Psychological Review, 98, 224-253.

Marsbach, H. (1973). Aspects of nonverbal communication in Japan. Journal of Nervous and Mental Disease, 157, 262-277.

Matsumoto, D. (1989). Cultural influences on the perception of emotion. Journal of CnossCultural Psychology, 20, 92-105.

Matsumoto, D. (1992). American-Japanese cultural differences in the recognition of universal facial expressions. Joumal of Cross-Cultural Psychology, 23, 72-84.

Matsumoto, D. (1993). Ethnic differences in affect intensity, emotion judgments, display rule attitudes, and self-reported emotional expression in an American sample. Motivation and Emotion, 17, 107-123.

Matsumoto, D., \& Ekman, P. (1989). American-Japanese cultural differences in intensity ratings of facial expressions of emotion. Motivation and Emotion, 13, 143-157.

Matsumoto, D., \& Kudoh, T. (1993). American-Japanese cultural differences in attributions of personality based on smiles. Journal of Nonverbal Behavior, 17, 231-243.

Matsumoto, D., Wallbott, H. G., \& Scherer, K. R. (1989). Emotions in intercultural communication. In M. K. Asante \& W. B. Gudykunst (Eds.), Handbook of intermational and intercultural communication (pp. 225-246). Newbury Park, CA: Sage.

Mehrabian, A., \& Russell, J. A. (1974). An approach to envinonmental psychology. Cambridge, MA: MIT Press.

Pittam, J., Kashima, Y., \& Iwawaki, S. (1990). Dimensionality and national function in Australian and Japanese ethnic stereotypes. Australian Journal of Psychology, 42, 297-308.

Pope, K. S. (1980). On love and loving. San Francisco: Jossey-Bass. 
Roseman, 1. J. (1984). Cognitive determinants of emotion: A structural theory. In P. Shaver (Ed.), Review of personality and social psychology: Vol. 5. Emotions, relationships and health (pp. 11-36). Beverly Hills, CA: Sage.

Russell, J. A. (1980). A circumplex model of affect. Journal of Personality and Social Psychology, 39, 1161-1178.

Russell, J. A. (1991). Culture and the categorization of emotion. Psychological Bulletin, I10, 426-450.

Russell, J. A. (1994). Is there universal recognition of emotion from facial expression? A review of the cross-cultural studies. Psychological Bulletin, II5, 102-141.

Russell, J. A., Lewicka, M., \& Niit, T. (1989). A cross-cultural study of a circumplex model of affect. Joumal of Personality and Social Psychology, 57, 848-856.

Scherer, K. R. (1982). Emotion as process: Function, origin and regulation. Social Science Information, 21, 555-570.

Scherer, K. R. (1985). Vocal affect signaling: A comparative approach. In J. S. Rosenblatt, C. Beer, M. C. Busnel, \& P.J.B. Slater (Eds.), Advances in the study of behavior: Vol. 15 (pp. 189-244). New York: Academic Press.

Scherer, K. R. (1986). Vocal affect expression: A review and a model for future research. Psychological Bulletin, 99, 143-165.

Scherer, K. R. (1988). On the symbolic functions of vocal affect expression. Journal of Language and Social Psychology, 7, 79-100.

Scherer, K. R., Wallbott, H. G., Matsumoto, D., \& Kudoh, T. (1988). Emotional experience in cultural context: A comparison between Europe, Japan, and the United States. In K. R. Scherer (Ed.), Facets of emotion: Recent research (pp. 5-30). Hillsdale, NJ: Lawrence Erlbaum.

Scherer, K. R., Wallbott, H. G., \& Summerfield, A. (Eds.). (1986). Experiencing emotion: A cross-cultural study. Cambridge: Cambridge University Press.

Shaver, P., Schwartz, J., Kirson, D., \& O'Connor, C. (1987). Emotion knowledge: Further exploration of a prototype approach. Journal of Personality and Social Psychology, 52, 1061-1086.

Shimoda, K., Argyle, M., \& Ricci-Bitti, P. (1978). The intercultural recognition of emotional expression by their national groups. European Journal of Social Psychology, 8, 169-179.

Smith, C. A., \& Ellsworth, P. C. (1985). Patterns of cognitive appraisal in emotion. Journal of Personality and Social Psychology, 48, 813-838.

Jeffery Pittam received his Ph.D. in vocal communication from the University of Queensland, Australia, where he currently is Senior Lecturer in Communication Studies. He researches in the areas of language and communication, being particularly concerned with ethnic identity and representations of HIVIAIDS, and vocal communication. He is author of Voice in Social Interaction (Sage, 1994).

Cynthia Gallois received her Ph.D. in social psychology and communication from the University of Florida. She is now a reader in psychology at the University of Queensland. Her research interests center on intercultural and intergroup (ethnicity, gender, sexual orientation) communication, especially in organizational and health contexts. She has published widely in these areas, including two recent books (with Keithia Wilson, 
Assertion and Its Social Context, Pergamon, 1993; with Deborah Terry and Malcolm McCamish, The Theory of Reasoned Action: Its Applications to AIDS-Prevention Behavior, Pergamon, 1993).

Saburo Iwawaki received his Ph.D. in personality psychology from Tohoku University and is Professor of Psychology at the Showa Women' University, Japan. His research interests include cross-cultural analyses of personality traits and social behavior.

Pieter Kroonenberg works as Statistician in the Department of Education at Leiden University, the Netherlands. He has a mathematics degree from Leiden University, where he also received his $P h . D$. in social sciences. His main research interests are methods for the analysis of continuous and discrete three-way data and the application of sophisticated data-analytic techniques to social science data. He has published in both methodological and substantive journals in a wide range of disciplines. 